JIPS, Vol. 1 No. 1

Halaman: $11-21$

Desember 2020
Jurnal Inovasi Pembelajaran di Sekolah

DOI: https://doi.org/10.51874/jips.v1i01.1

ISSN 2774-9363 (Cetak)

ISSN 2774-9746 (Online)

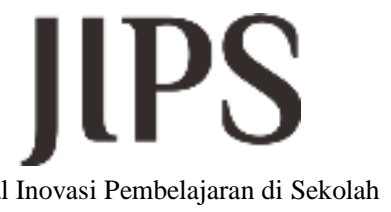

\title{
Peningkatan Kompetensi Menyusun Silabus Berbasis Pendidikan Budaya dan Karakter Bangsa Melalui Supervisi Akademik Saat PJJ Bagi Guru SMP 21 Semarang
}

\author{
Suwarno Agung Nugroho ${ }^{1 *}$ \\ ${ }^{1}$ SMP Negeri 21 Semarang \\ *Email: agungtito@gmail.com
}

\begin{abstract}
Abstrak
Pada saat terjadi pembelajaran jarak jauh (PJJ), ketika pandemi berlangsung, guru dituntut mampu menyusun silabus pembelajaran yang sesuai. Silabus pendidikan berbasis budaya dan karakter bangsa sangat dibutuhkan untuk membantu proses pembelajaran secara profesional saat PJJ. Peranan kepala sekolah dalam melakukan supervisi akademik untuk meningkatkan kompetensi menyusun silabus pendidikan budaya dan karakter bangsa menjadi sebuah kebutuhan. Berdasarkan permasalahan yang dihadapi guru-guru SMPN 21 Semarang, yaitu rendahnya kompetensi dalam menyusun silabus yang terintegrasi dengan pendidikan budaya dan karakter bangsa saat PJJ, maka perlu dicarikan solusinya. Untuk mengatasi masalah tersebut di atas, kepala sekolah perlu mengambil tindakan yang harus dilakukan yaitu melaksanakan pembinaan akademis tentang penyusunan silabus yang terintegrasi dengan pendidikan budaya dan karakter bangsa. Kurangnya pembekalan yang diberikan kepada guru dalam menyusun silabus Berbasis Pendidikan Budaya dan Karakter Bangsa perlu diatasi. Berdasarkan hasil pengamatan pada siklus I dengan dibandingkan pada siklus II tentang kompetensi menyusun silabus berbasis pendidikan budaya dan karakter bangsa pada guru SMPN 21 Semarang terdapat peningkatan kompetensi yang cukup baik meski pembelajaran dilakukan secara PJJ. Hal ini dapat dilihat dari rekapitulasi hasil pengamatan pada siklus II terdapat peningkatan kompetensi, 10 guru sudah bisa menyusun silabus berbasis pendidikan budaya dan karakter bangsa. Namun demikian, masih terdapat 2 guru yang belum bisa menyusun silabus. Dengan demikian, terdapat $83,3 \%$ guru sudah bisa menyusun kategori baik silabus berbasis pendidikan budaya dan karakter bangsa.Simpulan dari penelitian ini adalah melalui supervisi akademik saat PJJ dapat meningkatkan kompetensi menyusun silabus berbasis pendidikan budaya dan karakter bangsa
\end{abstract}

\section{Kata Kunci: Supervisi Akademik, Peningkatakan Kompetensi, Penyusunan Silabus}

\begin{abstract}
Abstrack
In the event of distance learning (PJJ), during the pandemic, teachers are required to be able to compile an appropriate learning syllabus. An educational syllabus based on culture and national character is needed to help the learning process professionally during PJJ. The role of the principal in conducting academic supervision to improve competence in compiling a syllabus for cultural education and national character is a necessity. Based on the problems faced by SMPN 21 Semarang teachers, namely the low competence in compiling a syllabus that is integrated with cultural education and national character during PJJ, it is necessary to find a solution. To overcome the problems mentioned above, school principals need to take actions that must be taken, namely carrying out academic coaching on the preparation of a syllabus that is integrated with cultural education and national character. The lack of provision for teachers in compiling a syllabus based on cultural education and national character needs to be addressed. Based on the results of observations in cycle I compared to the comparison in cycle II
\end{abstract}


regarding the competence of compiling a syllabus based on cultural education and national character for teachers of SMP N 21 Semarang, there is a fairly good increase in competence even though the learning is carried out in PJJ. This can be seen from the recapitulation of observations in cycle II, there is an increase in competence, 10 teachers have been able to compile a syllabus based on cultural education and national character. However, there are still 2 teachers who have not been able to compile a syllabus. Thus, there are $83.3 \%$ of teachers who have been able to compile categories both syllabus based on cultural education and national character. The conclusion of this research is through academic supervision when PJJ can improve the competence of compiling a syllabus based on cultural education and national character.

Keywords: Academic Supervision, Competence Improvement, Syllabus Compilation

\section{PENDAHULUAN}

Berdasarkan hasil pengumpulan silabus dan Rencana Pelaksanaan Pembelajaran (RPP) yang akan didokumentasikan pada Kurikulum 2013 pada awal tahun pelajaran 2020/2021 Sekolah Menengah Pertama Negeri (SMPN) 21 Semarang belum terkumpul, padahal telah disampaikan kepada guru untuk mengumpulkan silabus dan RPP pada tanggal 15 Juni 2020 pada acara pertemuan perdana dengan para guru. Motivasi guru untuk menyusun dan mengumpulkan silabus beserta RPP tidak menunjukkan semangat lebih cepat lebih baik, bahkan cenderung saling menunggu teman-temannya terlebih saat pandemi covid 19. Dari hasil pengamatan dan informasi yang didapat, tingkat kompetensi menyusun silabus dan RPP dapat dikatakan rendah, bahkan ada sebagian guru berada pada tingkatan yang sangat rendah. Hal ini dapat dilihat dari buku catatan pengumpulan silabus dan RPP.

Guru-guru di SMPN 21 Semarang yang sudah mengikuti bimbingan teknis menyusun silabus dan RPP yang terintegrasi dengan Pendidikan Budaya dan Karakter Bangsa memang baru sebagian kecil. Sementara Kepala Sekolah belum melakukan pembinaan akademis tentang bagaimana menyusun silabus dan RPP yang terintegrasi dengan Pendidikan Budaya dan Karakter Bangsa terlebih pada saat pandemi covid 19 pembelajaran dilakukan secara PJJ (pembelajaran jarak jauh). Kepala Sekolah baru melaksanakan pembinaan kepada para guru yang bersifat umum, seperti memotivasi guru untuk disiplin hadir di sekolah, disiplin masuk kelas sesuai jadwalnya. Sesuai dengan tugas pokok dan fungsinya, guru diharapkan mampu menyusun perencanaan pembelajaran, menyajikan pembelajaran, mengevaluasi, termasuk didalamnya menganalisis hasil evaluasi, serta menyusun dan melaksanakan program perbaikan dan pengayaan selama PJJ (pembelajaran jarak jauh).

Sesuai dengan tugas pokok dan fungsinya, kepala sekolah harus mampu menampilkan pribadi seorang pemimpin pendidikan, mengelola sekolah termasuk pendidik dan tenaga kependidikan, memiliki motivasi yang kuat untuk sukses dalam melaksanakan tugas pokok dan fungsinya sebagai pemimpin sekolah, melaksanakan supervisi akademik terhadap guru, dan menindak lanjuti hasil supervisi akademik terhadap guru dalam rangka peningkatan profesionalisme guru. Dengan melaksanakan tugas pokok dan fungsinya, kepala sekolah diharapkan mampu meningkatkan motivasi dan kompetensi guru dalam 
menyusun silabus dan RPP. Dalam praktis tugas kepala sekolah, berfungsi sebagai pembina akademis, dipandang perlu melakukan pembinaan akademis secara terus-menerus. Sehingga yang diharapkan kepala sekolah terhadap gurunya adalah profesional di dalam menjalankan tugas pokok dan fungsinya.

Berdasarkan permasalahan yang dihadapi guru-guru SMP N 21 Semarang, yaitu rendahnya kompetensi dalam menyusun silabus yang terintegrasi dengan pendidikan budaya dan karakter bangsa saat PJJ, maka perlu dicarikan solusinya. Untuk mengatasi masalah tersebut di atas, kepala sekolah perlu mengambil tindakan yang harus dilakukan yaitu melaksanakan pembinaan akademis tentang penyusunan silabus yang terintegrasi dengan pendidikan budaya dan karakter bangsa. Kurangnya pembekalan yang diberikan kepada guru dalam menyusun silabus Berbasis Pendidikan Budaya dan Karakter Bangsa perlu diatasi.

Tujuan penelitian ini adalah untuk meningkatkan kompetensi dalam menyusun silabus terintegrasi dengan pendidikan budaya dan karakter bangsa melalui pembinaan akademis bagi guru SMP N 21 Semarang semester 1 tahun pelajaran 2020/2021. Terlebih saat pembelajaran dilakukan secara jarak jauh atau BDR (belajar dari rumah).

Penelitian ini diharapkan bermanfaat bagi pemangku kepentingan dalam dunia pendidikan, yaitu sebagai berikut. Bagi guru diharapkan dapat meningkatkan motivasi dalam menyusun silabus. Meningkatknya kompetensi dalam menyusun silabus bagi guru-guru SMP N 21 Semarang agar lebih profesional. Bagi peneliti, melalui pembinaan akademis dapat meningkatkan motivasi dalam menyusun silabus yang terintegrasi dengan pendidikan budaya dan karakter bangsa bagi guru-guru SMP N 21 Semarang semester 1 tahun pelajaran 2020/2021. Melalui pembinaan akademis dapat meningkatkan kompetensi dalam menyusun silabus yang terintegrasi dengan pendidikan budaya dan karakter bangsa bagi guru-guru SMPN 21 Semarang semester 1 tahun pelajaran 2020/2021. Bagi Sekolah diharapkan dapat meningkatkan mutu perencanaan, pelaksanaan, dan evaluasi pembelajaran, sehingga dapat meningkatkan mutu hasil pembelajaran di SMP N 21 Semarang saat PJJ (pembelajaran jarak jauh) berlangsung.

\section{KAJIAN TEORI}

Silabus adalah rencana pembelajaran pada suatu dan/atau kelompok mata pelajaran/tema tertentu yang mencakup standar kompetensi, kompetensi dasar, materi pokok/pembelajaran, kegiatan pembelajaran, indikator pencapaian kompetensi untuk penilaian, penilaian, alokasi waktu dan sumber belajar (BSNP, 2016:2).

Kompetensi adalah kemampuan seseorang yang meliputi pengetahuan, sikap, dan keterampilan (PP No.19 Tahun 2005). Kompetensi bagi seorang guru adalah seperangkat tindakan cerdas, penuh tanggung jawab yang harus dimiliki seorang guru sebagai syarat untuk dianggap mampu dalam melaksanakan tugas di bidang pendidikan (PP No. 19 Tahun 2005). Kompetensi guru ini dikembangkan secara utuh dari empat kompetensi utama, yaitu kompetensi pedagogik, kepribadian, sosial, dan 
profesional. Keempat kompetensi tersebut terintegrasi dalam kinerja guru (Permendiknas No. 16 tahun 2007). Dalam penelitian ini konsep kompetensi yang digunakan merujuk PP No. 19 Tahun 2005 tentang Standar Nasional Pendidikan, yaitu kemampuan seseorang yang meliputi pengetahuan, sikap, dan keterampilan.

Budaya diartikan sebagai keseluruhan sistem berpikir, nilai, moral, norma, dan keyakinan manusia yang dihasilkan masyarakat. Sistem berpikir, nilai, moral, norma, dan keyakinan itu adalah hasil dari interaksi manusia dengan sesamanya dan lingkungan alamnya. Sistem berpikir, nilai, moral, norma, dan keyakinan itu digunakan dalam kehidupan manusia dan menghasilkan sistem sosial, sistem ekonomi, sistem kepercayaan, sistem pengetahuan, teknologi, seni, dan sebagainya (Pusat Kurikulum, 2015:3). Karakter adalah watak, tabiat, akhlak, atau kepribadian seseorang yang terbentuk dari hasil internalisasi berbagai kebajikan yang diyakini dan digunakan sebagai landasan untuk cara pandang, berpikir, bersikap, dan bertindak. Kebajikan terdiri atas sejumlah nilai, moral, dan norma, seperti jujur, berani bertindak, dapat dipercaya, dan hormat kepada orang lain. Interaksi seseorang dengan orang lain menumbuhkan karakter masyarakat dan karakter bangsa (Pusat Kurikulum, 2015:3).

Pendidikan merupakan suatu usaha yang sadar dan sistematis dalam mengembangkan potensi peserta didik. Pendidikan adalah juga suatu usaha masyarakat dan bangsa dalam mempersiapkan generasi mudanya bagi keberlangsungan kehidupan masyarakat dan bangsa yang lebih baik di masa depan. Keberlangsungan itu ditandai oleh pewarisan budaya dan karakter yang telah dimiliki masyarakat dan bangsa (Pusat Kurikulum, 2015:4). Atas dasar pemikiran itu, pengembangan pendidikan budaya dan karakter sangat strategis bagi keberlangsungan dan keunggulan bangsa di masa mendatang. Pengembangan itu harus dilakukan melalui perencanaan yang baik, pendekatan yang sesuai, dan metode belajar serta pembelajaran yang efektif. Sesuai dengan sifat suatu nilai, pendidikan budaya dan karakter bangsa adalah usaha bersama sekolah, oleh karenanya harus dilakukan secara bersama oleh semua guru dan pemimpin sekolah, melalui semua mata pelajaran, dan menjadi bagian yang tak terpisahkan dari budaya sekolah (Pusat Kurikulum, 2015:4). Silabus berbasis pendidikan budaya dan karakter bangsa adalah rencana pembelajaran pada suatu dan/atau kelompok mata pelajaran/tema tertentu yang mencakup standar kompetensi, kompetensi dasar, materi pokok/pembelajaran, kegiatan pembelajaran, indikator pencapaian kompetensi untuk penilaian, penilaian, alokasi waktu, dan sumber belajar yang bertujuan untuk mengembangkan nilai-nilai budaya pada diri peserta didik melalui pendidikan hati, otak dan fisik.

Ada bermacam-macam konsep supervisi. Cartel (Sahertian, 2015:17) member pengertian bahwa supervisi adalah usaha dari petugas-petugas sekolah dalam memimpin guru-guru dan petugas-petugas lainnya dalam memperbaiki pengajaran, termasuk menstimulasi, menyelesaikan pertumbuhan jabatan dan perkembangan guru-guru serta merevisi tujuan-tujuan pendidikan. Pendapat lain yang dikemukakan Purwanto (2017:76) bahwa supervisi adalah segala bantuan dari para pemimpin sekolah, yang tertuju kepada perkembangan kepemimpinan guru-guru dan personel sekolah lainnya di dalam mencapai tujuantujuan pendidikan. Berdasarkan pendapat-pendapat tersebut dapat disimpulkan bahwa supervisi adalah 
suatu aktivitas pembinaan yang direncanakan untuk membantu para guru dan pegawai sekolah lainnya dalam melakukan pekerjaan mereka secara efektif.

\section{METODE PENELITIAN}

Penelitian ini dilaksanakan mulai dari perencanaan sampai dengan pelaporan kurang lebih tiga bulan, Juli sampai dengan September 2020. Bulan Juli digunakan untuk menyusun bab 1, 2 dan 3, bulan Agustus digunakan untuk menyusun instrumen. Untuk pelaksanaan Siklus I pada minggu kesatu, kedua dan ketiga; Siklus II pada minggu keempat Agustus, dan minggu kesatu serta kedua September 2020. Bulan September digunakan untuk pembahasan dan pembuatan laporan. Penelitian ini dilaksanakan di SMP N 21 Semarang. Alasan peneliti memilih SMP N 21 Semarang sebagai tempat penelitian ini karena peneliti sebagai guru dan sekaligus mendapat tugas tambahan sebagai Kepala Sekolah yang mempunyai tugas pokok dan fungsi salah satunya adalah melaksanakan supervisi di sekolah.

Subjek penelitian dalam penelitian tindakan sekolah ini adalah guru-guru Mata Pelajaran kelas VII di SMP N 21 Semarang sebanyak 12 orang dari total seluruh guru 46 orang. Pengambilan subjek 12 orang untuk lebih memudahkan proses penelitian, sehingga data yang diperoleh lebih spesifik.

Tabel 3.1 Daftar Guru Mata Pelajaran Sebagai Subjek Penelitian

\begin{tabular}{|c|l|c|l|}
\hline NO & \multicolumn{1}{|c|}{ NAMA } & L/ P & \multicolumn{1}{|c|}{ MATA PELAJARAN } \\
\hline 1 & Dita Fitrianingrum, S.Pd. & P & Bahasa Indonesia \\
\hline 2 & Lilis Endah Lupiani, S.Pd. & P & Bahasa Inggris \\
\hline 3 & Indah Heriyani, S.Pd. & P & Bahasa Jawa \\
\hline 4 & Istingadah, S.Pd. & P & Matematika \\
\hline 5 & Dra. Nur Widyastuti & P & Ilmu Pengetahuan Alam \\
\hline 6 & Wahyunto, S.Ag & L & Pendidikan Agama Islam \\
\hline 7 & Untari, S.Pd. & P & Seni Budaya \\
\hline 8 & Fiska Emila, S.Sos. & P & Bimbingan Konseling \\
\hline 9 & Herman Rahmawanto, S.Pd. & L & PPKn \\
\hline 10 & Sujarwo, S.Pd. & L & Ilmu Pengetahuan Sosial \\
\hline 11 & Soeprapto, S.Kom. & L & $\begin{array}{l}\text { Teknologi } \\
\text { Knformasi }\end{array}$ \\
\hline 12 & Dita Try Oktaviyanti, M.Pd. & P & Muatan Lokal \\
\hline
\end{tabular}

Sumber data dalam penelitian ini adalah: data primer yang didapat dari hasil observasi dan tes tulis pada guru mata pelajaran SMPN 21 Semarang dengan lembar observasi dan butir tes yang dilakukan oleh peneliti mengggunakan google form. Bentuk data kuantitatif berupa hasil penilaian kompetensi guru dalam menyusun silabus. Banyaknya data ada enam, yaitu: data motivasi guru dalam menyusun silabus pada kondisi awal, data kompetensi guru dalam menyusun silabus pada kondisi awal, data motivasi guru dalam menyusun silabus pada siklus I, data kompetensi guru dalam menyusun silabus pada siklus I, data motivasi guru dalam menyusun silabus pada siklus II dan data kompetensi guru dalam menyusun silabus pada siklus II. Teknik dan alat pengumpulan data pada kondisi awal adalah dokumentasi dan dokumen 
untuk mengungkap motivasi guru dalam menyusun silabus berupa catatan guru yang sudah mengumpulkan silabus dan RPP. Untuk data kompetensi guru dalam menyusun silabus juga menggunakan teknik dokumentasi dan alat pengumpul data dokumen yang berupa print out silabus dan RPP yang dikumpulkan guru pada pembantu kepala sekolah bidang kurikulum. Teknik dan alat pengumpulan data pada siklus I dan II adalah observasi dan lembar observasi tentang motivasi guru dalam menyusun silabus. Untuk data kompetensi guru dalam menyusun silabus menggunakan teknik tes tertulis dan alat pengumpul data berupa butir soal tes tertulis yang dilengkapi format penilaian dan kriteria penilaian. Data kompetensi guru dalam menyusun silabus dalam siklus I maupun siklus II yang diperoleh melalui teknik tes tertulis divalidasi dengan menggunakan validitas isi dengan cara membuat kisi-kisi.

\section{HASIL DAN PEMBAHASAN}

\section{HASIL}

Untuk lebih jelasnya tentang gambaran kondisi awal Guru SMPN 21 Semarang semester 1 Tahun Pelajaran 2020/2021 perhatikan tabel dan gambar berikut.

Tabel 4.1 Catatan Guru yang Sudah Mengumpulkan Silabus dan RPP Berbasis Pendidikan Budaya dan Karakter Bangsa Kondisi Awal

\begin{tabular}{|c|c|c|c|c|}
\hline No. & Nama Guru & Mata Pelajaran & Baik & $\begin{array}{l}\text { Kurang } \\
\text { Baik }\end{array}$ \\
\hline 1 & Dita Fitrianingrum, S.Pd. & Bahasa Indonesia & & $\mathrm{V}$ \\
\hline 2 & $\begin{array}{l}\text { Lilis Endah Lupiani, } \\
\text { S.Pd. }\end{array}$ & Bahasa Inggris & & $\mathrm{V}$ \\
\hline 3 & Indah Heriyani, S.Pd. & Bahasa Jawa & & $\mathrm{V}$ \\
\hline 4 & Istingadah, S.Pd. & Matematika & $\mathrm{V}$ & \\
\hline 5 & Dra. Nur Widyastuti & Ilmu Pengetahuan Alam & & $\mathrm{V}$ \\
\hline 6 & Wahyunto, S.Ag & Pendidikan Agama Islam & & $\mathrm{V}$ \\
\hline 7 & Untari, S.Pd. & Seni Budaya & $\mathrm{V}$ & \\
\hline 8 & Fiska Emila, S.Sos. & Bimbingan Konseling & & $\mathrm{V}$ \\
\hline 9 & $\begin{array}{l}\text { Herman Rahmawanto, } \\
\text { S.Pd. }\end{array}$ & PPKn & & $\mathrm{V}$ \\
\hline 10 & Sujarwo, S.Pd. & Ilmu Pengetahuan Sosial & & $\mathrm{V}$ \\
\hline 11 & Soeprapto, S.Kom. & $\begin{array}{lll}\text { Teknologi } & \text { Informasi } & \text { dan } \\
\text { Komunikasi } & & \end{array}$ & $\mathrm{V}$ & \\
\hline 12 & $\begin{array}{l}\text { Dita Try Oktaviyanti, } \\
\text { M.Pd. }\end{array}$ & Muatan Lokal & $\mathrm{V}$ & \\
\hline
\end{tabular}




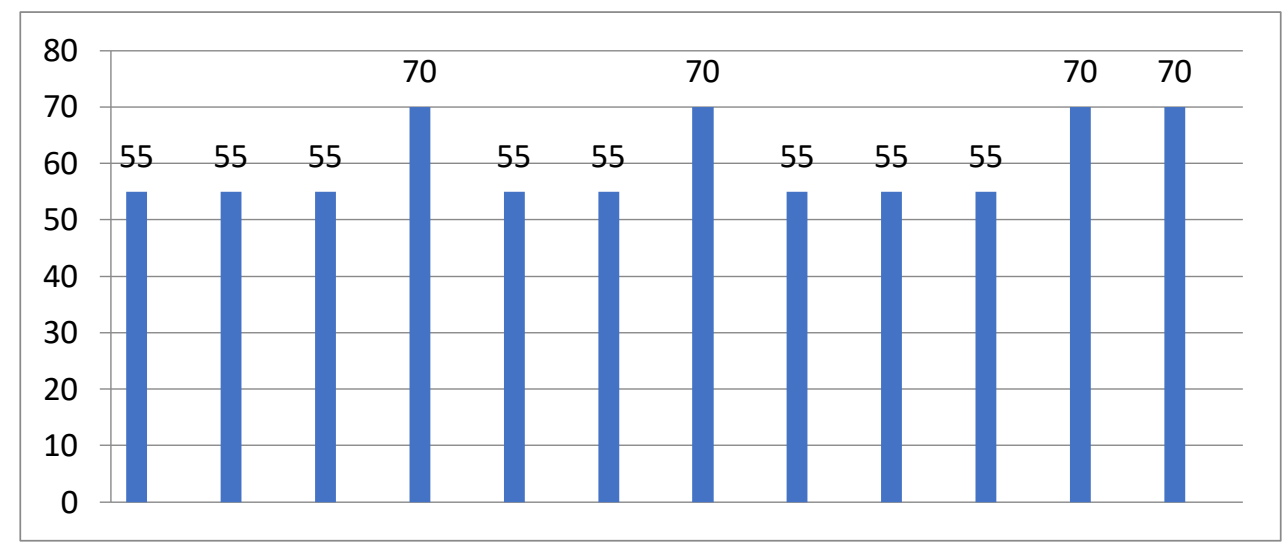

Gambar 4.1 Skor Penilaian Silabus Berbasis Pendidikan Budaya dan Karakter Bangsa Kondisi Awal

Tindakan pembinaan akademis dalam rangka meningkatkan kompetensi menyusun silabus berbasis pendidikan budaya dan karakter bangsa bagi guru-guru SMP N 21 Semarang yang dilakukan oleh peneliti, secara umum mereka memperhatikan penjelasan dengan seksama. Teknik yang digunakan dalam mengungkap kompetensi menyusun silabus adalah tes tertulis. Berdasarkan hasil tes tertulis tentang menyusun silabus berbasis pendidikan budaya dan karakter bangsa didapat data sebagaimana tabel dan gambar berikut.

Tabel 4.2 Hasil Tes Tertulis Menyusun Silabus Berbasis Pendidikan Budaya dan Karakter Bangsa Siklus

\begin{tabular}{|c|c|c|c|c|}
\hline No. & Nama Guru & Mata Pelajaran & Baik & $\begin{array}{c}\text { Kurang } \\
\text { Baik }\end{array}$ \\
\hline 1 & Dita Fitrianingrum, S.Pd. & Bahasa Indonesia & V & \\
\hline 2 & $\begin{array}{l}\text { Lilis Endah Lupiani, } \\
\text { S.Pd. }\end{array}$ & Bahasa Inggris & V & \\
\hline 3 & Indah Heriyani, S.Pd. & Bahasa Jawa & & $\mathrm{V}$ \\
\hline 4 & Istingadah, S.Pd. & Matematika & V & \\
\hline 5 & Dra. Nur Widyastuti & Ilmu Pengetahuan Alam & & $\mathrm{V}$ \\
\hline 6 & Wahyunto, S.Ag & Pendidikan Agama Islam & & $\mathrm{V}$ \\
\hline 7 & Untari, S.Pd. & Seni Budaya & V & \\
\hline 8 & Fiska Emila, S.Sos. & Bimbingan Konseling & & $\mathrm{V}$ \\
\hline 9 & $\begin{array}{l}\text { Herman Rahmawanto, } \\
\text { S.Pd. }\end{array}$ & PPKn & V & \\
\hline 10 & Sujarwo, S.Pd. & Ilmu Pengetahuan Sosial & & $\mathrm{V}$ \\
\hline 11 & Soeprapto, S.Kom. & $\begin{array}{lll}\text { Teknologi } & \text { Informasi } & \text { dan } \\
\text { Komunikasi } & & \end{array}$ & V & \\
\hline 12 & $\begin{array}{l}\text { Dita Try Oktaviyanti, } \\
\text { M.Pd. }\end{array}$ & Muatan Lokal & V & \\
\hline
\end{tabular}




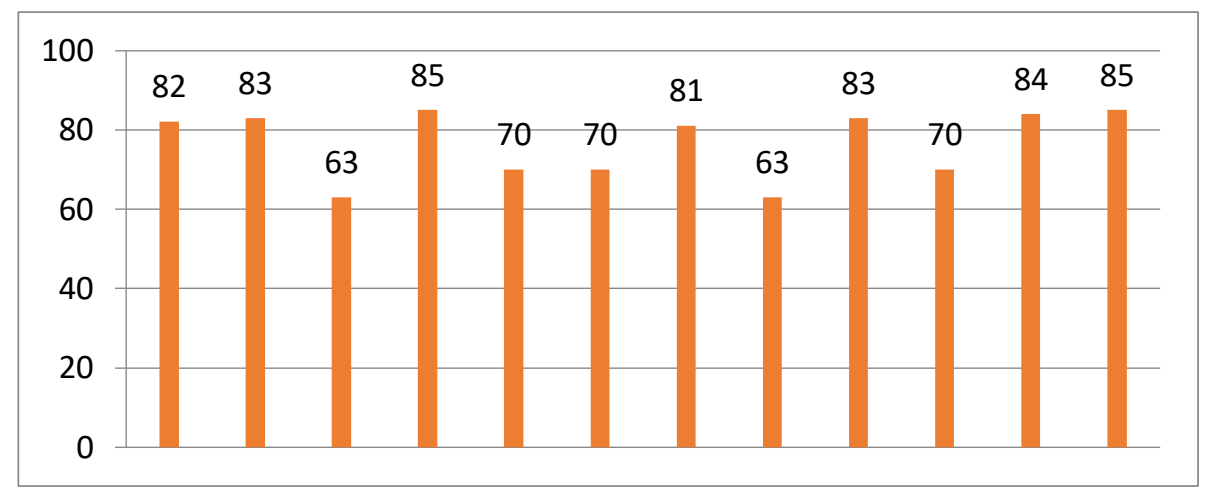

Gambar 4.2 Hasil Tes Kompetensi Menyusun Silabus Berbasis Pendidikan Budaya dan Karakter Bangsa Siklus I

Dari tabel dan gambar tersebut di atas tentang hasil tes tertulis kompetensi menyusun silabus berbasis pendidikan budaya dan karakter bangsa pada siklus I dapat dijelaskan sebagai berikut. Guru SMP N 21 Semarang yang sudah bisa menyusun dengan kategori baik silabus berbasis pendidikan budaya dan karakter bangsa sebanyak 7 orang, sedang yang belum bisa atau kategori kurang baik sebanyak 5 orang. Dengan demikian, terdapat 58,3\% guru sudah bisa menyusun dengan kategori baik silabus berbasis pendidikan budaya dan karakter bangsa.

Selama pelaksanaan tindakan pembinaan akademis pada siklus II dalam rangka meningkatkan kompetensi menyusun silabus berbasis pendidikan budaya dan karakter bangsa bagi guru-guru SMP N 21 Semarang yang dilakukan oleh peneliti, secara umum guru-guru memperhatikan penjelasan dengan seksama. Ada beberapa guru yang mengajukan pertanyaan berkaitan dengan pembetulan penyusunan silabus berbasis pendidikan budaya dan karakter bangsa. Pertanyaan yang diajukan guru adalah "bagaimana merumuskan kalimat kegiatan pembelajaran dengan memasukkan nilai-nilai budaya pada silabus?". Selanjutnya peneliti menjawab pertanyaan tersebut dengan memberi contoh rumusan kalimat kegiatan pembelajaran dengan memasukkan nilai-nilai budaya. Pertanyaan lain yang disampaikan oleh guru adalah " bagaimana merumuskan kalimat indikator dengan memasukkan nilai-nilai budaya pada silabus?". Peneliti langsung menjawab dengan memberi contoh merumuskan kalimat indikator dengan memasukkan nilai-nilai budaya pada silabus. Berdasarkan hasil tes tertulis tentang menyusun silabus berbasis pendidikan budaya dan karakter bangsa didapat data sebagaimana tabel berikut.

Tabel 4.3 Hasil Tes Tertulis Menyusun Silabus Berbasis Pendidikan Budaya dan Karakter Bangsa Siklus II

\begin{tabular}{|c|l|l|c|c|}
\hline No. & \multicolumn{1}{|c|}{ Nama Guru } & \multicolumn{1}{|c|}{ Mata Pelajaran } & Baik & $\begin{array}{c}\text { Kurang } \\
\text { Baik }\end{array}$ \\
\hline 1 & Dita Fitrianingrum, S.Pd. & Bahasa Indonesia & V & \\
\hline 2 & $\begin{array}{l}\text { Lilis Endah Lupiani, } \\
\text { S.Pd. }\end{array}$ & Bahasa Inggris & V & \\
\hline 3 & Indah Heriyani, S.Pd. & Bahasa Jawa & & V \\
\hline 4 & Istingadah, S.Pd. & Matematika & V & \\
\hline 5 & Dra. Nur Widyastuti & Ilmu Pengetahuan Alam & V & \\
\hline
\end{tabular}




\begin{tabular}{|c|c|c|c|c|}
\hline 6 & Wahyunto, S.Ag & Pendidikan Agama Islam & $\mathrm{V}$ & \\
\hline 7 & Untari, S.Pd. & Seni Budaya & $\mathrm{V}$ & \\
\hline 8 & Fiska Emila, S.Sos. & Bimbingan Konseling & & $\mathrm{V}$ \\
\hline 9 & $\begin{array}{l}\text { Herman Rahmawanto, } \\
\text { S.Pd. }\end{array}$ & PPKn & V & \\
\hline 10 & Sujarwo, S.Pd. & Ilmu Pengetahuan Sosial & $\mathrm{V}$ & \\
\hline 11 & Soeprapto, S.Kom. & $\begin{array}{lll}\text { Teknologi } & \text { Informasi } & \text { dan } \\
\text { Komunikasi } & & \end{array}$ & $\mathrm{V}$ & \\
\hline 12 & $\begin{array}{l}\text { Dita Try Oktaviyanti, } \\
\text { M.Pd. }\end{array}$ & Muatan Lokal & $\mathrm{V}$ & \\
\hline
\end{tabular}

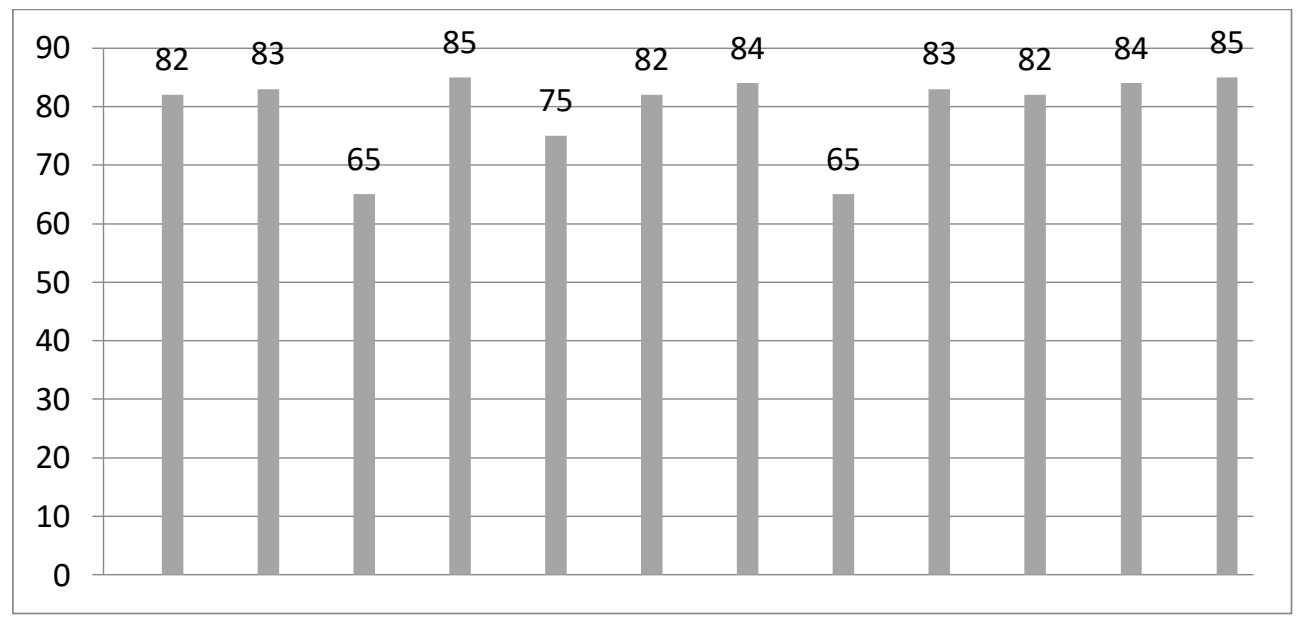

Gambar 4.3 Hasil Tes Kompetensi Menyusun Silabus Berbasis Pendidikan Budaya dan Karakter Bangsa Siklus II

Dari tabel dan gambar tersebut di atas tentang hasil tes tertulis kompetensi menyusun silabus berbasis pendidikan budaya dan karakter bangsa pada siklus 2 dapat dijelaskan. Guru SMPN 21 Semarang yang sudah bisa menyusun dengan kategori baik silabus berbasis pendidikan budaya dan karakter bangsa sebanyak 10 orang, sedang yang belum bisa atau kategori kurang baik sebanyak 2 orang. Dengan demikian, terdapat $83,3 \%$ guru sudah bisa menyusun kategori baik silabus berbasis pendidikan budaya dan karakter bangsa.

\section{PEMBAHASAN}

Berdasarkan hasil pengamatan pada siklus I dengan dibandingkan pada siklus II tentang kompetensi menyusun silabus berbasis pendidikan budaya dan karakter bangsa pada guru SMPN 21 Semarang terdapat peningkatan kompetensi yang cukup baik meski pembelajaran dilakukan secara PJJ. Hal ini dapat dilihat dari rekapitulasi hasil pengamatan pada siklus II terdapat peningkatan kompetensi, 10 guru sudah bisa menyusun silabus berbasis pendidikan budaya dan karakter bangsa. Namun demikian, masih terdapat 2 guru yang belum bisa menyusun silabus. Hal-hal yang positif dalam peningkatan kompetensi melalui tindakan pembinaan akademis pada siklus II akan dipertahankan, bahkan jika perlu ditingkatkan. Hal-hal yang kurang dapat meningkatkan kompetensi dikurangi, bahkan jika perlu ditiadakan karena menggunakan suplemen kurikulum darurat. Bertolak dari permasalahan yang dihadapi 
guru-guru SMP N 21 Semarang, dicarikan solusi untuk membantu menyelesaikan masalah yaitu berupa tindakan kepala sekolah melakukan supervisi akademik dengan tindak lanjut pembinaan akademik. Harapannya, melalui supervisi akademik dengan tindak lanjut pembinaan akademik yang dilakukan kepala sekolah terhadap guru-guru SMP N 21 Semarang, motivasi dan kompetensinya meningkat, sehingga mampu menyusun silabus berbasis pendidikan budaya dan karakter bangsa meski dalam suasana pandemi covid 19.

\section{PENUTUP}

Berdasarkan hasil dan pembahasan dari penelitian ini dapat disimpulkan bahwa melalui supervisi akademik dengan tindak lanjut pembinaan akademik dapat meningkatkan kompetensi menyusun silabus berbasis pendidikan budaya dan karakter bangsa bagi guru SMPN 21 Semarang Semester 1 Tahun 2020/2021 saat pembelajaran jarak jauh (PJJ). Berdasarkan simpulan tersebut di atas, dapat direkomendasikan sebagai berikut. Bagi Guru Mata Pelajaran perlu membangun komitmen yang tinggi agar pelaksanaan tugas pokok dan fungsinya semakin mantap. Guru SMPN 21 Semarang perlu meningkatkan kompetensi kepribadian, pedagogis, profesional, dan sosial yang tinggi agar mampu melaksanakan tugas pokoknya secara maksimal. Bagi Kepala Sekolah perlu meningkatkan kompetensi kepribadian, manajerial, supervisi, kewirausahaan, dan sosial agar mampu melaksanakan tugas pokok dan fungsinya secara maksimal. Kepala sekolah perlu memberikan penghargaan bagi guru yang berprestasi dan membina guru yang kurang berprestasi. Bagi Dinas Pendidikan Kota Semarang perlu memberikan penghargaan bagi guru dan kepala sekolah yang berprestasi. Perlu menyelenggarakan workshop peningkatan kompetensi guru secara berkesinambungan. Pengawas satuan pendidikan perlu melaksanakan tugas pokok dan fungsinya secara maksimal.

\section{DAFTAR PUSTAKA}

Arikunto, Suharjono, dan Supardi. 2016. Penelitian Tindakan Kelas. Jakarta: Bumi Aksara.

Arikunto. 2018. Dasar-dasar Administrasi dan Supervisi Pendidikan. Jakarta: Bumi Aksara.

Badan Standar Nasional Pendidikan. 2016. Panduan Penyususnan Kurikulum Tingkat Satuan Pendidikan Jenjang Pendidikan Dasar dan Menengah. Jakarta: Badan Standar Nasional Pendidikan.

Hartoyo. 2016. Supervisi Pendidikan Mewujudkan Sekolah Efektif dalam Kerangka Manajemen Berbasis Sekolah. Semarang: Pelita Insani.

Kemdikbud. 2018. Kamus Besar Bahasa Indonesia. Jakarta: Pusat Bahasa.

Permendiknas No. 16 Tahun 2007 Tentang Standar Kualifikasi Akademik dan Kompetensi Guru.

PP Nomor 19 Tahun 2005. Standar Nasional Pendidikan.

Purwanto. 2017. Administrasi dan Supervisi Pendidikan. Bandung: Rodakarya. 
Pusat Kurikulum. 2015. Pendidikan Budaya dan Karakter Bangsa. Jakarta: Kementerian Pendidikan dan Kebudayaan.

Sahertian. 2015. Konsep Dasar dan Teknik Supervisi Pendidikan dalam rangka Pengembangan Sumberdaya Manusia. Jakarta: Rineka Cipta.

Soemanto. 2018. Psikologi Pendidikan Landasan Kerja Pemimpin Pendidikan. Jakarta: Rineka Cipta. 